\title{
Low-Temperature Strengths and Ductility of Various Tungsten Sheets
}

\author{
Yutaka Hiraoka ${ }^{1}$ and Hiroaki Kurishita ${ }^{2}$ \\ ${ }^{1}$ Department of Applied Physics, Okayama University of Science, 1-1 Ridai-cho, Okayama 700-0005, Japan \\ ${ }^{2}$ International Research Center for Nuclear Materials Science, IMR, Tohoku University, Ibaraki, Oarai 311-1313, Japan
}

Correspondence should be addressed to Yutaka Hiraoka, hiraoka@dap.ous.ac.jp

Received 18 March 2011; Accepted 6 June 2011

Academic Editor: Kin Ho Lo

Copyright (C) 2011 Y. Hiraoka and H. Kurishita. This is an open access article distributed under the Creative Commons Attribution License, which permits unrestricted use, distribution, and reproduction in any medium, provided the original work is properly cited.

\begin{abstract}
We used three kinds of tungsten sheets in this study. First, we examined microstructure such as grain size distribution using an optical microscope. Secondly, we carried out three-point bend tests at temperatures between about 290 and $500 \mathrm{~K}$. Then, we examined fracture surface of a failed specimen using a scanning electron microscope. Lastly, by analyzing all these results, we evaluated apparent intergranular and transgranular fracture strengths and discussed strengths and ductility of tungsten. Additionally, we compared mechanical properties of tungsten with those of molybdenum.
\end{abstract}

\section{Introduction}

Generally, pure molybdenum after recrystallization indicates a certain amount of ductility at room temperature. In contrast, pure tungsten after recrystallization does not deform plastically near room temperature, since its ductile-to-brittle transition temperature is much above $400 \mathrm{~K}$ [1]. Such brittleness of tungsten is principally attributed to high hardness which leads to high yield strength and difficulty of plastic deformation. However, detailed discussion on such difference in the strengths and ductility between tungsten and molybdenum has not been carried out until now.

Materials used in this study are pure tungsten, K-doped tungsten, and La-doped tungsten. All these materials are subjected to recrystallization treatments in various conditions. First, we examined microstructure such as average grain size and size distribution of the specimen after recrystallization using an optical microscope (OM). Secondly, we carried out three-point bend tests at temperatures between about $290 \mathrm{~K}$ and $500 \mathrm{~K}$ and obtained yield and maximum strengths. From the temperature dependences of the yield and the maximum strengths, we evaluated two parameters (critical stress and critical temperature) $[2,3]$. Lastly, we carried out fracture surface observation of a failed specimen by a scanning electron microscope (SEM). Analyzing these experimental data, we estimated apparent intergranular and/or transgranular fracture strengths. Furthermore, we compared and discussed difference in the mechanical properties between tungsten and molybdenum.

\section{Experimental Procedures}

Three kinds of tungsten sheets were used in this study. One is pure tungsten sheet (designated as " $\mathrm{W}$ " in the text). The others are K-doped tungsten sheet (K: about 50 mass ppm, designated as "KDW" in the text) and La-doped tungsten sheet $\left(\mathrm{La}_{2} \mathrm{O}_{3}\right.$ : about 1 mass $\%$, designated as "LDW" in the text). Thickness of these sheets is about $1 \mathrm{~mm}$. The materials are produced by powder metallurgy, sintered, hot-rolled, and stress relieved. Typical grain structure of these materials is a fibrous structure. Before the following measurements, the materials were subjected to recrystallization treatments in various conditions. Pure tungsten sheet was heated at $1773 \mathrm{~K}$ for $3.6 \mathrm{ks}$ or at $2073 \mathrm{~K}$ for $3.6 \mathrm{ks}$ in a vacuum of less than $10^{-5}$ torr. Two doped tungsten sheets were heated at $2073 \mathrm{~K}$ for $3.6 \mathrm{ks}$ in vacuum. In the test, heat treatments at 1773 for $3.6 \mathrm{ks}$ and at $2073 \mathrm{~K}$ for $3.6 \mathrm{ks}$ were designated as "r1" and "r2," respectively. For example, K-doped tungsten after recrystallization at $2073 \mathrm{~K}$ for $3.6 \mathrm{ks}$ is designated as "KDW(r2)." 


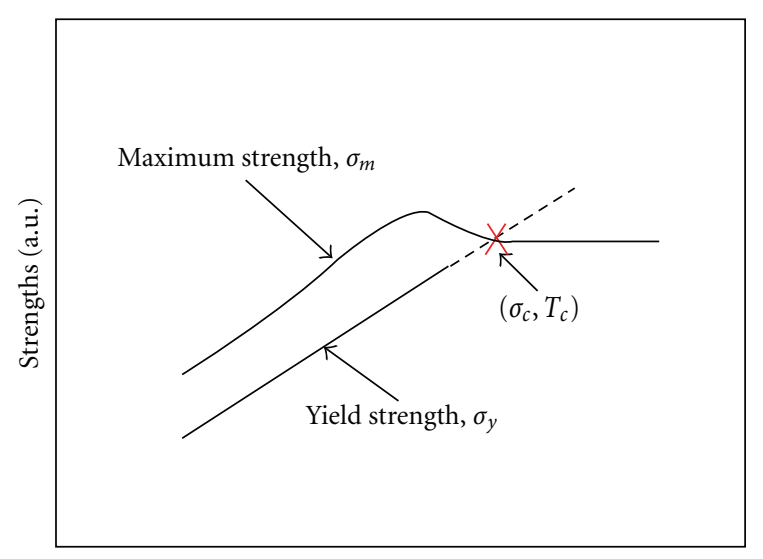

Reciprocal of temperature (a.u.)

FIgURE 1: Definition of critical stress and critical temperature.

We examined microstructure of the material using OM. Grain shape is approximately equiaxial. Thereby we measured grain size in the direction parallel to the final rolling direction and determined average grain size and its distribution.

We evaluated mechanical properties of the material by three-point bend tests. We carried out the tests at a strain rate of $2 \times 10^{-4} \mathrm{~s}^{-1}$ at a temperature between about $290 \mathrm{~K}$ and $500 \mathrm{~K}$. We obtained yield strength $\left(\sigma_{y}\right)$ and maximum strength $\left(\sigma_{m}\right)$ using the following:

$$
\begin{aligned}
\sigma_{y} & =\frac{3 a F_{y}}{w t^{2}}, \\
\sigma_{m} & =\frac{3 a F_{m}}{w t^{2}} .
\end{aligned}
$$

$F_{y}$ and $F_{m}$ are the load at the yield point and maximum load point, respectively. $2 a(=16 \mathrm{~mm})$ is the support span. $w$ and $t$ are the specimen width and thickness, respectively. In this study, typical specimen width and thickness were $4 \mathrm{~mm}$ and $1 \mathrm{~mm}$, respectively. Here, we automatically converted the bend strength $\left(\sigma_{b t}\right)$ to the tensile strength $\left(\sigma_{t t}\right)$ using the following equation. This equation was experimentally obtained [4]:

$$
\sigma_{t t}=\frac{\sigma_{b t}}{1.74} .
$$

From temperature dependence of the yield and maximum strengths, we estimated two parameters (critical stress, $\sigma_{c}$ and critical temperature, $\left.T_{c}\right)[2,3]$. These parameters are derived as schematically shown in Figure 1. Critical stress is a stress which is necessary to generate and propagate microcracks alternatively along the grain boundaries or in the matrix. This stress corresponds to apparent intergranular fracture strength of a polycrystalline material. Critical temperature, on the other hand, is an expression of ductileto-brittle transition temperature (DBTT), and reciprocal of this temperature corresponds to low-temperature ductility. Higher value of $\left(1 / T_{c}\right)$ means the material is more "ductile" and even at a lower temperature.

We determined fracture mode as follows. We observed the fracture surface of a specimen which failed in a brittle manner at about $290 \mathrm{~K}$ using SEM. In this study, we represent the fracture mode by a parameter, PIF-value. PIF-value is a percent intergranular fracture value and is defined as a ratio of intergranular fracture area to total fracture area. For example, a high PIF-value means grain boundaries of the material are generally very weak. For molybdenum with an average grain size of $20-25 \mu \mathrm{m}$, critical stress $\left(\sigma_{c}\right)$ and fracture mode (PIF-value) demonstrate the following relationship $[2,3]$ :

$$
\text { PIF-value }=0.2\left(k-\sigma_{c}\right) .
$$

Here, the constant $k$ corresponds to apparent transgranular fracture strength, since the value of $k$ at PIF-value $=0$ means a stress which is necessary to propagate microcracks only in the matrix.

\section{Results}

3.1. Grain Size and Its Distribution. Grain size distribution of the material is shown in Figures 2(a) (W(r1)), 2(b) (W(r2)), $2(\mathrm{c})(\mathrm{KDW}(\mathrm{r} 2))$, and $2(\mathrm{~d})(\mathrm{LDW}(\mathrm{r} 2))$. Average grain size is also indicated in the figure. Grain size distributions of $\mathrm{W}(\mathrm{r} 1)$ and $\mathrm{KDW}(\mathrm{r} 2)$ are similar. Average grain sizes of these materials are almost the same, and their distributions were relatively narrow. Grain size distributions of $\mathrm{W}(\mathrm{r} 2)$ and LDW(r2) are generally different from $\mathrm{W}(\mathrm{r} 1)$ and $\mathrm{KDW}(\mathrm{r} 2)$. The former materials indicate much larger grain size and much wider size distribution than the latter. At first, these results suggest that grain coarsening occurred after heating at a higher temperature in case of pure tungsten. Secondly, $\mathrm{K}$-doping and La-doping suppressed grain coarsening to a certain extent.

3.2. Strengths and Ductility. Temperature dependences of the strengths are shown in Figure 3 (yield strength) and Figure 4 (maximum strength).

Yield strength of pure tungsten significantly depends on the heating condition. Yield strength of $\mathrm{W}(\mathrm{r} 2)$ which was heated at $2073 \mathrm{~K}$ is generally much lower than that of $\mathrm{W}(\mathrm{r} 1)$ which was heated at $1773 \mathrm{~K}$. Yield strength of $\mathrm{KDW}(\mathrm{r} 2)$ is approximately the same as that of $\mathrm{W}(\mathrm{r} 1)$. Yield strength of $\operatorname{LDW}(\mathrm{r} 2)$ is slightly lower than that of $\mathrm{W}(\mathrm{r} 1)$ and/or $\mathrm{KDW}(\mathrm{r} 2)$, but higher than that of $\mathrm{W}(\mathrm{r} 2)$.

Maximum strength of pure tungsten also significantly depends on the heating condition. Maximum strength of $\mathrm{W}(\mathrm{r} 2)$ is generally much lower than that of $\mathrm{W}(\mathrm{r} 1)$. Maximum strengths of $\mathrm{KDW}(\mathrm{r} 2)$ and $\operatorname{LDW}(\mathrm{r} 2)$ are ranging between $\mathrm{W}(\mathrm{r} 1)$ and $\mathrm{W}(\mathrm{r} 2)$, although strength of $\mathrm{KDW}(\mathrm{r} 2)$ is higher than that of $\operatorname{LDW}(\mathrm{r} 2)$.

Critical stress and critical temperature are summarized in Table 1. We obtained these parameters in a manner as already shown in Figure 1. First, critical stress approximately corresponds to the maximum strength. Critical stress of $\mathrm{W}(\mathrm{r} 1)$ is much higher than that of $\mathrm{W}(\mathrm{r} 2)$. Critical stresses of $\mathrm{KDW}(\mathrm{r} 2)$ and $\mathrm{LDW}(\mathrm{r} 2)$ are ranging between $\mathrm{W}(\mathrm{r} 1)$ and $\mathrm{W}(\mathrm{r} 2)$, although stress of $\mathrm{KDW}(\mathrm{r} 2)$ is higher than that of $\operatorname{LDW}(\mathrm{r} 2)$. Critical temperature, on the other hand, does not necessarily follow the critical stress or the maximum strength. Difference in the critical temperature 


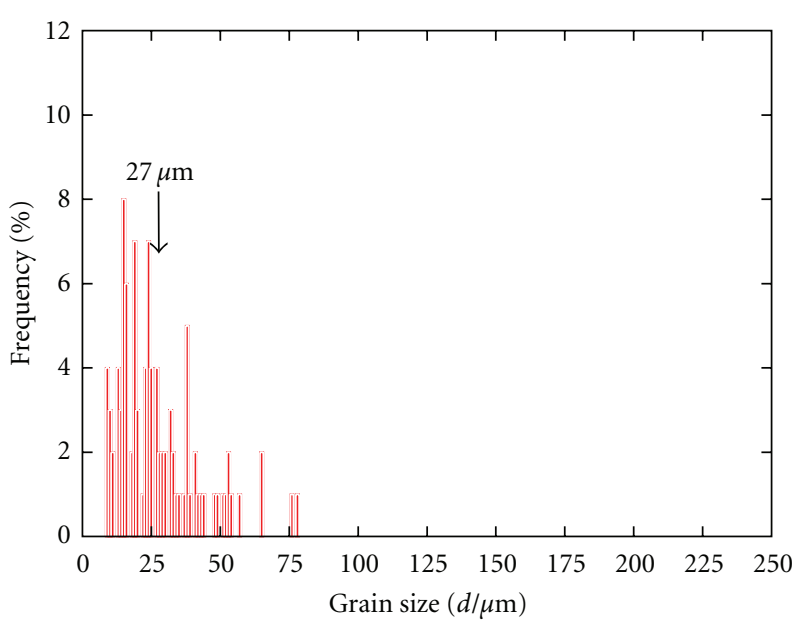

(a) $\mathrm{W}(\mathrm{r} 1)$

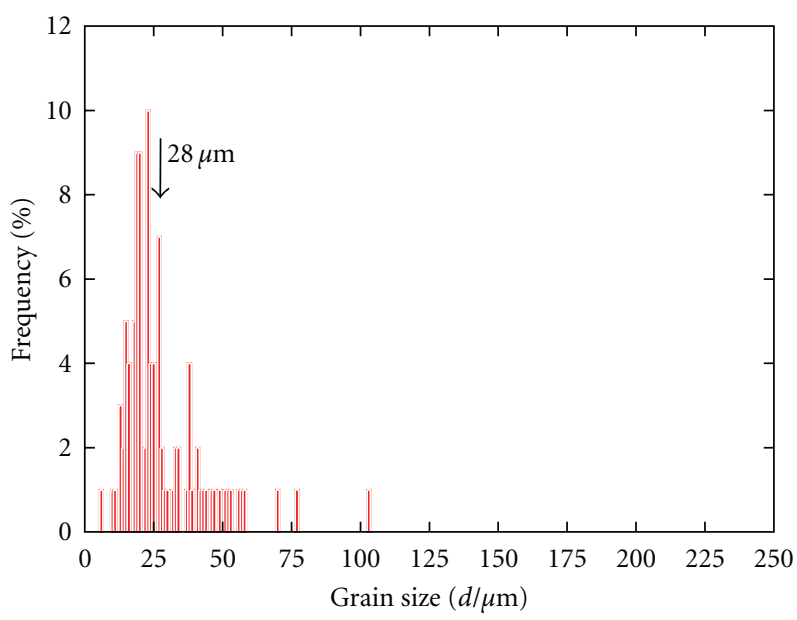

(c) $\operatorname{KDW}(\mathrm{r} 2)$

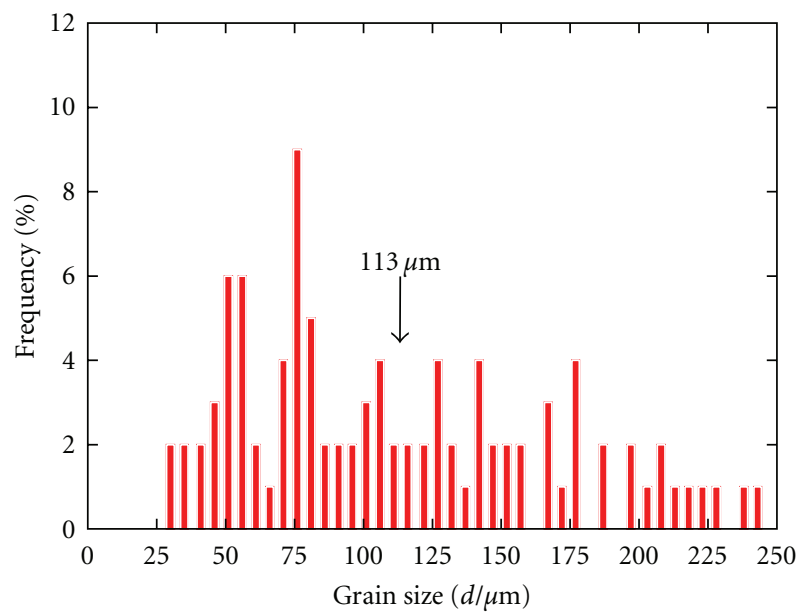

(b) $\mathrm{W}(\mathrm{r} 2)$

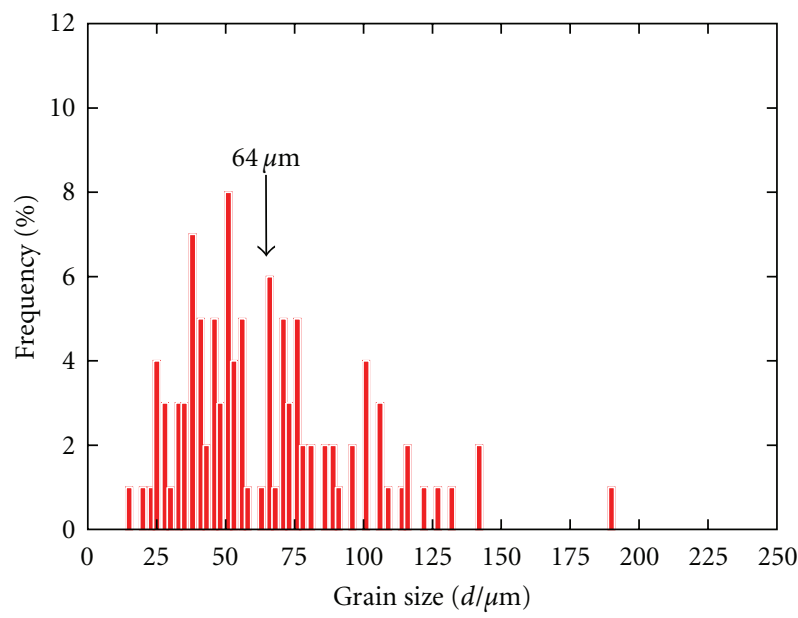

(d) $\operatorname{LDW}(\mathrm{r} 2)$

FIGURE 2: Grain size distributions for various materials.

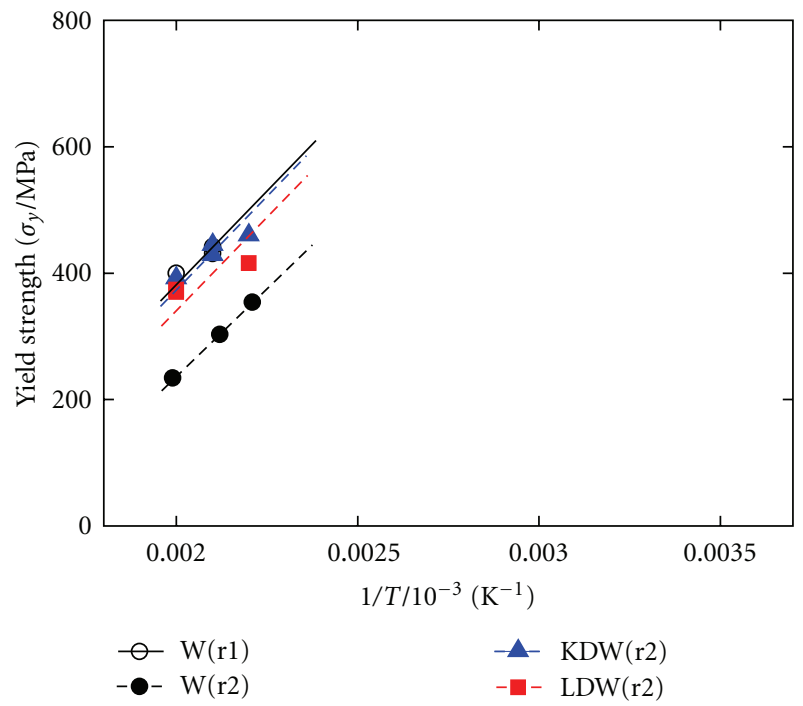

Figure 3: Plots of yield strength against test temperature for various materials.

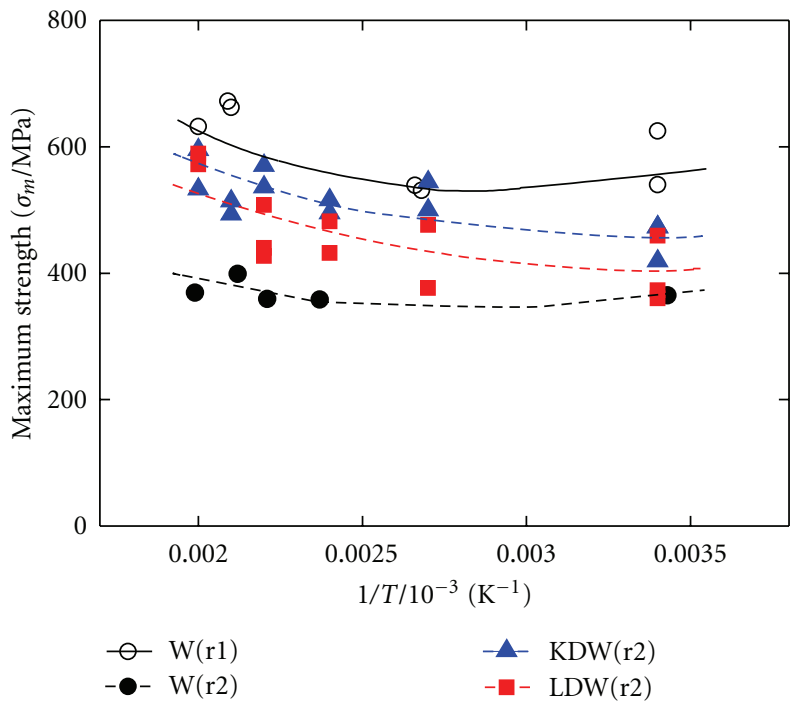

FIgURE 4: Plots of maximum strength against test temperature for various materials. 

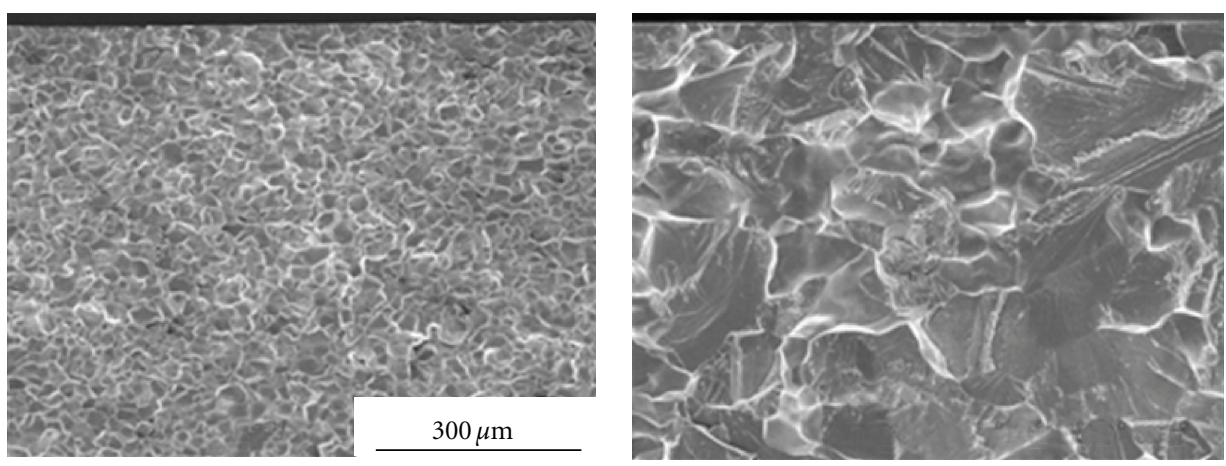

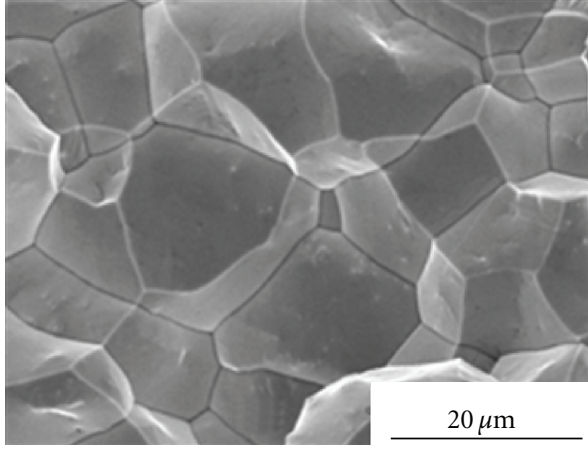

(a) $\mathrm{W}(\mathrm{r} 1)$
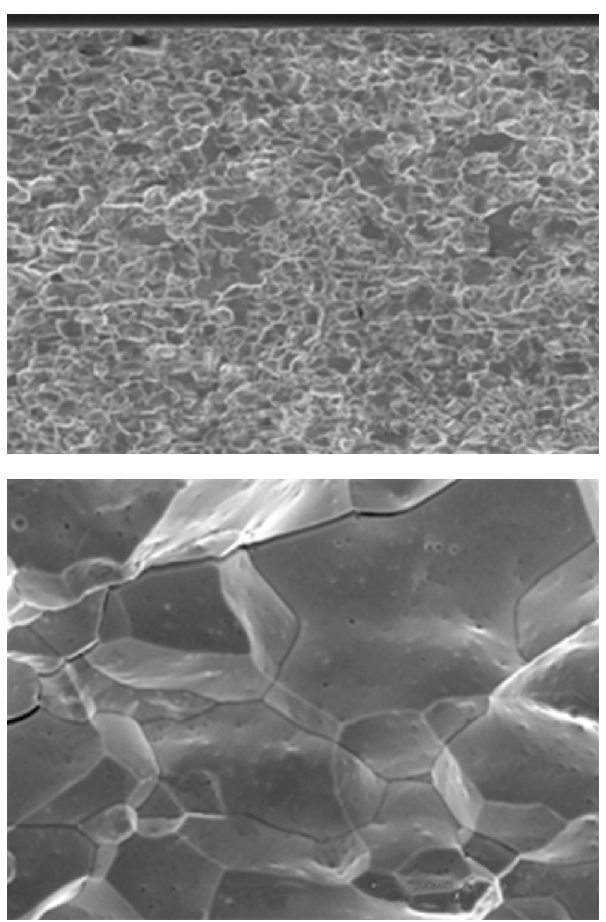

(c) $\mathrm{KDW}(\mathrm{r} 2)$

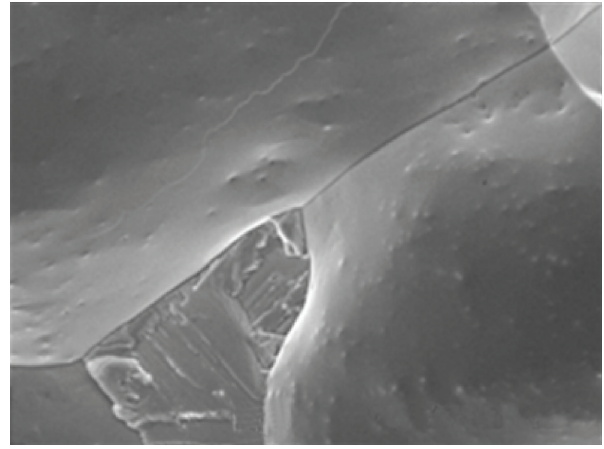

(b) $\mathrm{W}(\mathrm{r} 2)$
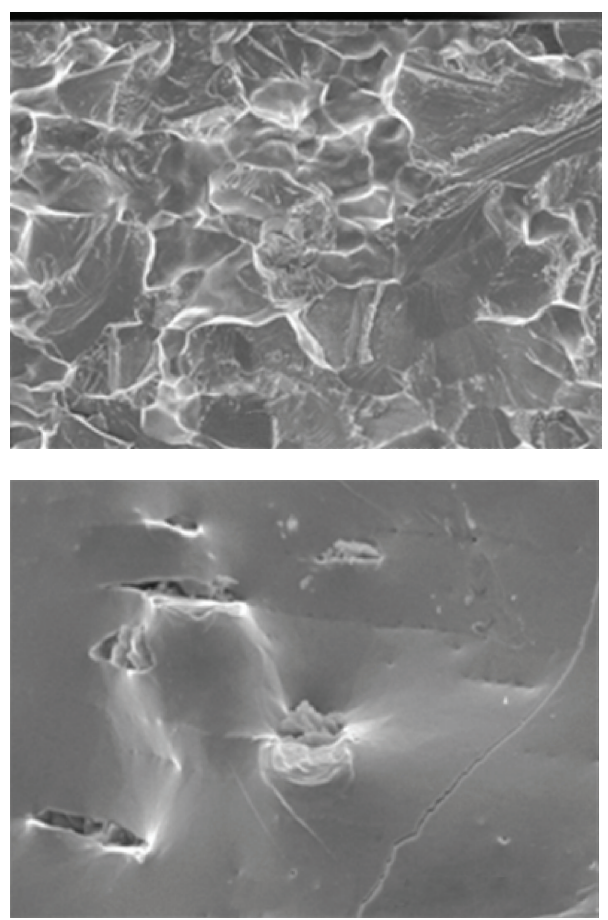

(d) $\operatorname{LDW}(\mathrm{r} 2)$

Figure 5: Typical fracture surfaces of various materials.

among materials is considerably little in contrast to that in the critical stress. This result is well interpreted, since the critical temperature is determined not only by the maximum strength (critical stress) but by the yield strength. In contrast, the critical stress is determined almost only by the maximum strength $[2,3]$.
3.3. Fracture Mode. Typical fracture modes of various tungsten are shown in Figures $5(\mathrm{a})(\mathrm{W}(\mathrm{r} 1)), 5(\mathrm{~b})(\mathrm{W}(\mathrm{r} 2))$, $5(\mathrm{c})(\mathrm{KDW}(\mathrm{r} 2))$, and $5(\mathrm{~d})(\operatorname{LDW}(\mathrm{r} 2))$. Fracture modes of $\mathrm{W}(\mathrm{r} 1)$ and $\mathrm{KDW}(\mathrm{r} 2)$ are principally intergranular fracture. On the other hand, fracture modes of W(r2) and LDW(r2) are mixture of intergranular and transgranular fracture. 
TABLE 1: Summaries of critical stress, critical temperature, and PIFvalue for various materials.

\begin{tabular}{lccc}
\hline Materials & $\begin{array}{c}\text { Critical stress } \\
\sigma_{c} / \mathrm{MPa}\end{array}$ & $\begin{array}{c}\text { Critical temperature } \\
T_{c} / \mathrm{K}\end{array}$ & $\begin{array}{c}\text { PIF-value } \\
(\%)\end{array}$ \\
\hline $\mathrm{W}(\mathrm{r} 1)$ & 585 & 430 & 85 \\
$\mathrm{~W}(\mathrm{r} 2)$ & 370 & 450 & 60 \\
$\mathrm{KDW}(\mathrm{r} 2)$ & 530 & 440 & 93 \\
$\mathrm{LDW}(\mathrm{r} 2)$ & 475 & 450 & 57 \\
\hline
\end{tabular}

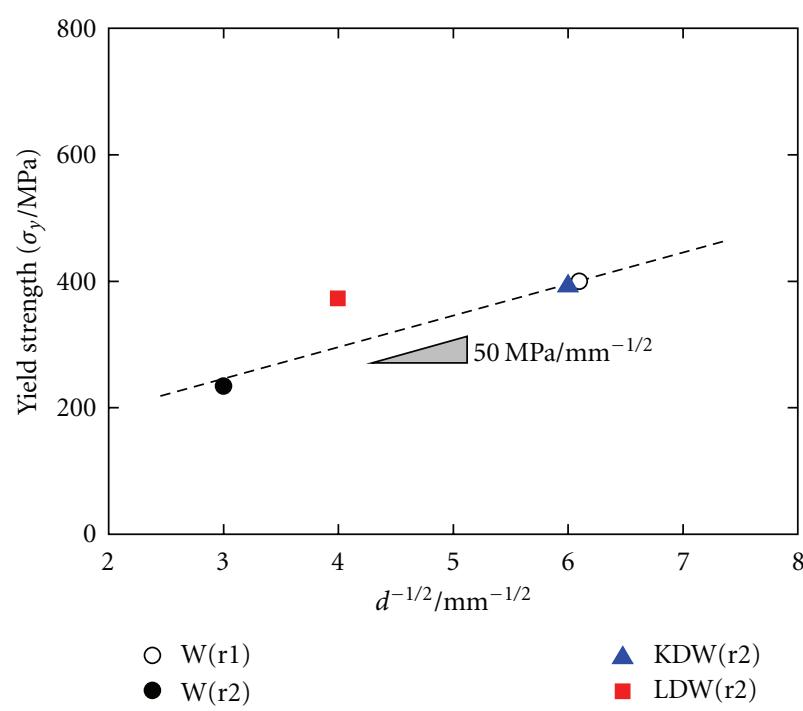

Figure 6: Grain size dependence of yield strength for various materials.

By a high-magnification SEM observation, intergranular fracture surfaces of $\mathrm{W}(\mathrm{r} 1)$ and $\mathrm{W}(\mathrm{r} 2)$ are relatively clean, except for a number of very small pores. General aspect of the intergranular fracture surfaces of $\mathrm{KDW}(\mathrm{r} 2)$ is similar to $\mathrm{W}(\mathrm{r} 1)$ and $\mathrm{W}(\mathrm{r} 2)$. On the other hand, some coarse inclusions are recognized on the intergranular fracture surfaces of $\operatorname{LDW}(\mathrm{r} 2)$. Considering the heating temperature of $2073 \mathrm{~K}$, it is supposed that these inclusions are $\mathrm{La}_{2} \mathrm{O}_{3}$ particles.

Using fracture surface photographs, we determined PIFvalue. Average values are summarized also in Table 1. PIFvalues of $\mathrm{W}(\mathrm{r} 1)$ and $\mathrm{KDW}(\mathrm{r} 2)$ are as high as about $90 \%$ similar to pure molybdenum after recrystallization [5]. On the other hand, PIF-values of $\mathrm{W}(\mathrm{r} 2)$ and $\mathrm{LDW}(\mathrm{r} 2)$ are medium (about 60\%).

\section{Discussion}

4.1. Grain Size Dependence of Yield Strength and Critical Stress. It is well known that strength of a material is significantly affected by the microstructure such as grain size. For example, Hall-Petch relationship stands between the yield strength and the grain size [6]. Thereby we discussed grain size dependence of the yield strength and critical stress in this session.

In Figure 6, yield strength obtained at about $500 \mathrm{~K}$ is plotted against the reciprocal of square root of grain size (d). In this study, average grain size was used as the grain

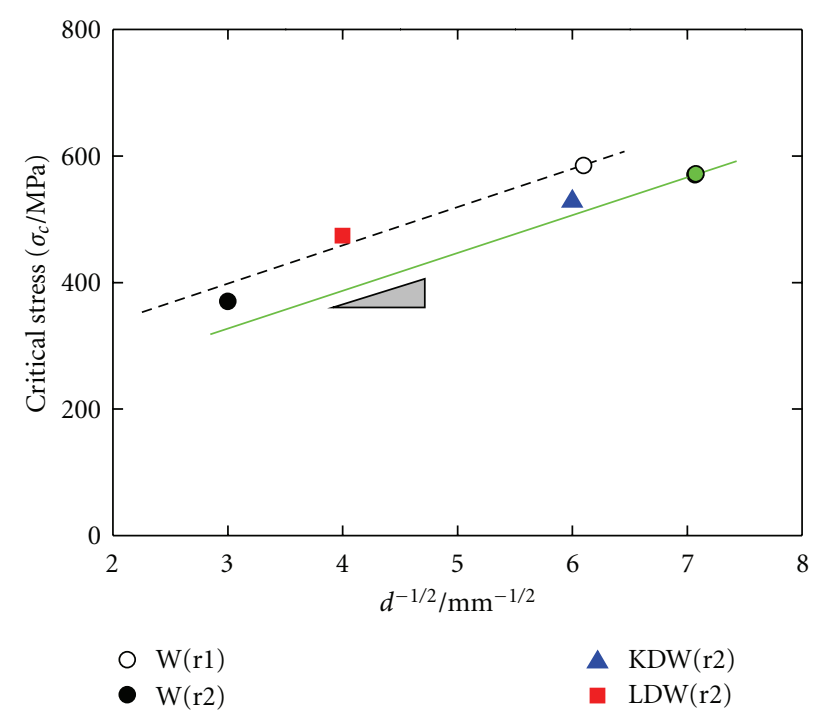

FIGURE 7: Grain size dependence of critical stress for various materials.

size. Dotted line in the figure indicates a linear relationship between the yield strength at $500 \mathrm{~K}$ and the reciprocal of grain size that was reported by Yih and Wang [7]. Data of various tungsten are well consistent with the linear relationship, although data of $\operatorname{LDW}(\mathrm{r} 2)$ is slightly higher. The latter result might be attributed to the dispersion of inclusions as shown in Figure 5(d).

In Figure 7, critical stress is plotted against the reciprocal of square root of grain size. In this study, the critical stress corresponds to the fracture strength of a material at a relatively low temperature. There is no data concerning the contribution of grain size to the critical stress or to the fracture strength in tungsten. Therefore, we applied the results obtained for molybdenum with grain size of $20-25 \mu \mathrm{m}$ (green solid line) [8]. It is obvious that data for tungsten qualitatively agree with the relationship for molybdenum.

4.2. Relationship between Critical Stress and Fracture Mode. In Figure 8, PIF-value is plotted against critical stress. Data obtained for molybdenum with grain size of 20-25 $\mathrm{m}$ [5] is also plotted in the figure for reference. In addition, the green line having a slope of 0.2 represents linear relationship between the critical stress and the fracture mode for molybdenum $[5,8]$.

It is interesting that data of $\mathrm{W}(\mathrm{r} 1)$ and $\mathrm{KDW}(\mathrm{r} 2)$ approximately agree with the green line obtained for molybdenum. It is noted that all these materials have grain sizes almost as large as $20-25 \mu \mathrm{m}$. Present result suggests, at first, that relationship between the PIF-value and the critical stress is applicable not only to molybdenum but also to tungsten. Secondly, intergranular fracture strength of $\mathrm{KDW}(\mathrm{r} 2)$ is slightly lower than that of $\mathrm{W}(\mathrm{r} 1)$ with their transgranular fracture strengths being equivalent with each other.

Data of W(r2) and LDW(r2) deviate left hand from the linear relationship. This result might be attributed to the contribution of grain size to the intergranular and transgranular fracture strength (the constant, $k$ in (3)), although 


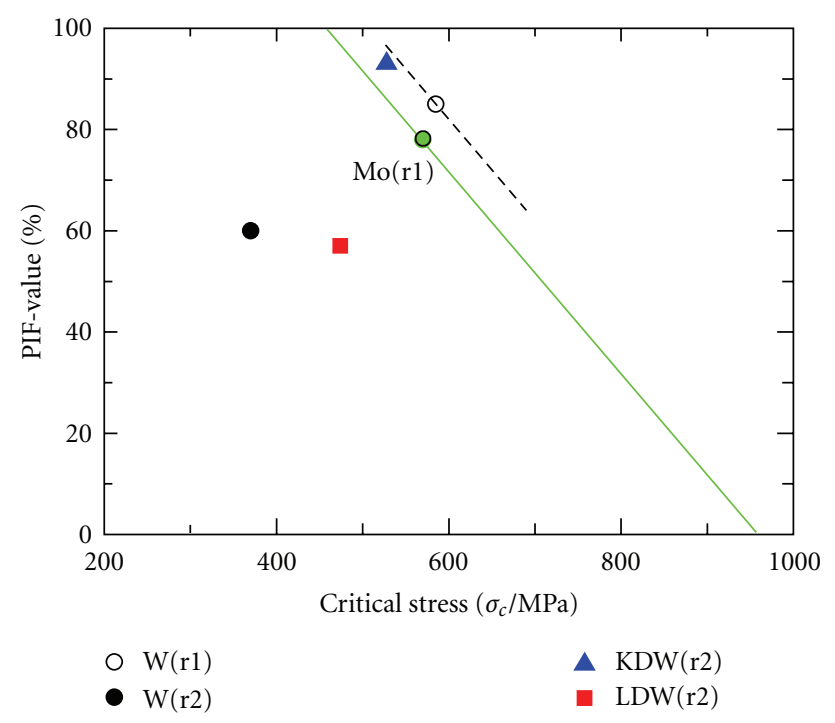

FIGURE 8: Plots of PIF-value against critical stress for various materials.

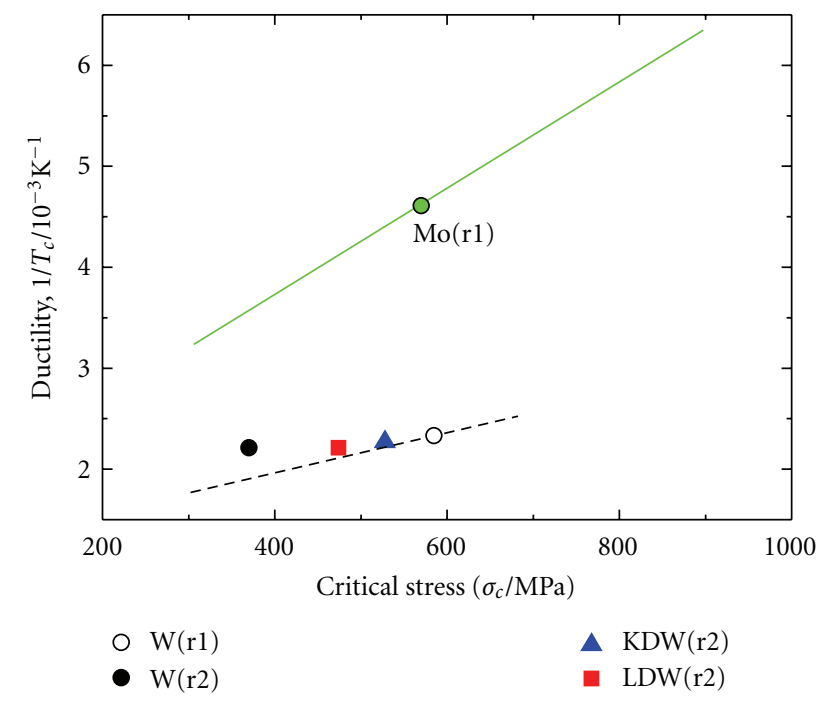

Figure 9: Plots of ductility $\left(1 / T_{c}\right)$ against critical stress for various materials.

contribution of grain size on the transgranular fracture strength for tungsten has not been reported yet. Grain coarsening concurrently induces lowering of transgranular fracture strength as well as lowering of intergranular fracture strength. As a result, PIF-value is almost unchanged.

4.3. Plots of Critical Stress and Reciprocal of Critical Temperature. As already mentioned, the critical stress corresponds to the apparent intergranular fracture strength. On the other hand, the critical temperature is an expression of ductile-tobrittle transition temperature (DBTT), and the reciprocal of critical temperature is a measure of ductility [2].

In Figure 9, reciprocal of critical temperature (ductility) is plotted against critical stress. Data obtained for molybdenum [5] is also plotted in the figure for comparison. At first, it is obvious that ductility of tungsten is generally much lower than that of molybdenum. This result is principally interpreted by the difference of yield strength between molybdenum and tungsten. It is known that yield strength of tungsten is much higher than that of molybdenum at a given temperature with the grain size being equivalent. The straight line in the figure indicates the temperature dependence of the yield strength. Secondly, intergranular fracture strength of tungsten is almost equivalent with that of molybdenum if the grain size is the same.

\section{Summaries of Results}

(1) Yield strength of tungsten principally depends on the microstructure such as grain size. Yield strength of tungsten at a given temperature is much higher than that of molybdenum.

(2) Critical stress of tungsten depends not only on the grain size but also on the intergranular fracture strength. Critical stress of tungsten is almost equivalent with that of molybdenum if the grain size is the same.

(3) Low-temperature ductility of tungsten is determined both by the yield strength and the maximum strength (critical stress). As a result, ductility of tungsten is generally much lower than that of molybdenum.

\section{Acknowledgment}

The authors greatly appreciate Dr. Tomohiro Takida and A.L.M.T. Corp for supplying pure tungsten and doped tungsten materials.

\section{References}

[1] 8: Tungsten, in Behavior and Properties of Refractory Metals, T. E. Tietz and J. W. Wilson, Eds., pp. 274-330, University of Tokyo Press, Tokyo, Japan, 1965.

[2] Y. Hiraoka, S. Yoshimura, and K. Takebe, "Effects of complex additions of Re or Ti with $\mathrm{C}$ on the strength and ductility of recrystallized molybdenum," International Journal of Refractory Metals and Hard Materials, vol. 12, no. 5, pp. 261-268, 1993.

[3] S. Yoshimura, Y. Hiraoka, and K. Takebe, "Effect of Ti in solution on ductile-brittle transition characteristics of powder-metallurgy molybdenum alloys," Journal of the Japan Institute of Metals, vol. 58, no. 7, pp. 734-739, 1994 (Japanese).

[4] T. Hoshika, S. Yoshimura, and Y. Hiraoka, "Evaluation of lowtemperature fracture characteristics of molybdenum by means of tensile tests and bend tests," in Proceedings of the 14th intergranular Plansee Sem, pp. 1018-1025, Tirol, Austria, 1997.

[5] T. Kadokura, Y. Hiraoka, Y. Yamamoto, and K. Okamot, "Change of mechanical property and fracture mode of molybdenum by carbon addition," Materials Transactions, vol. 51, no. 7, pp. 1296-1301, 2010.

[6] N. J. Petch, “The cleavage strength of polycrystals," The Journal of the Iron and Steel Institute, vol. 173, pp. 25-27, 1953. 
[7] S. W. H. Yih and C. T. Wang, Tungsten- Sources, Metallurgy, Properties, and Applications, Plenum, New York, NY, USA, 1977.

[8] Y. Hiraoka, "Significant effect of carbon content in the lowtemperature fracture behavior of molybdenum," Materials Transactions, vol. 31, no. 10, pp. 861-864, 1990. 

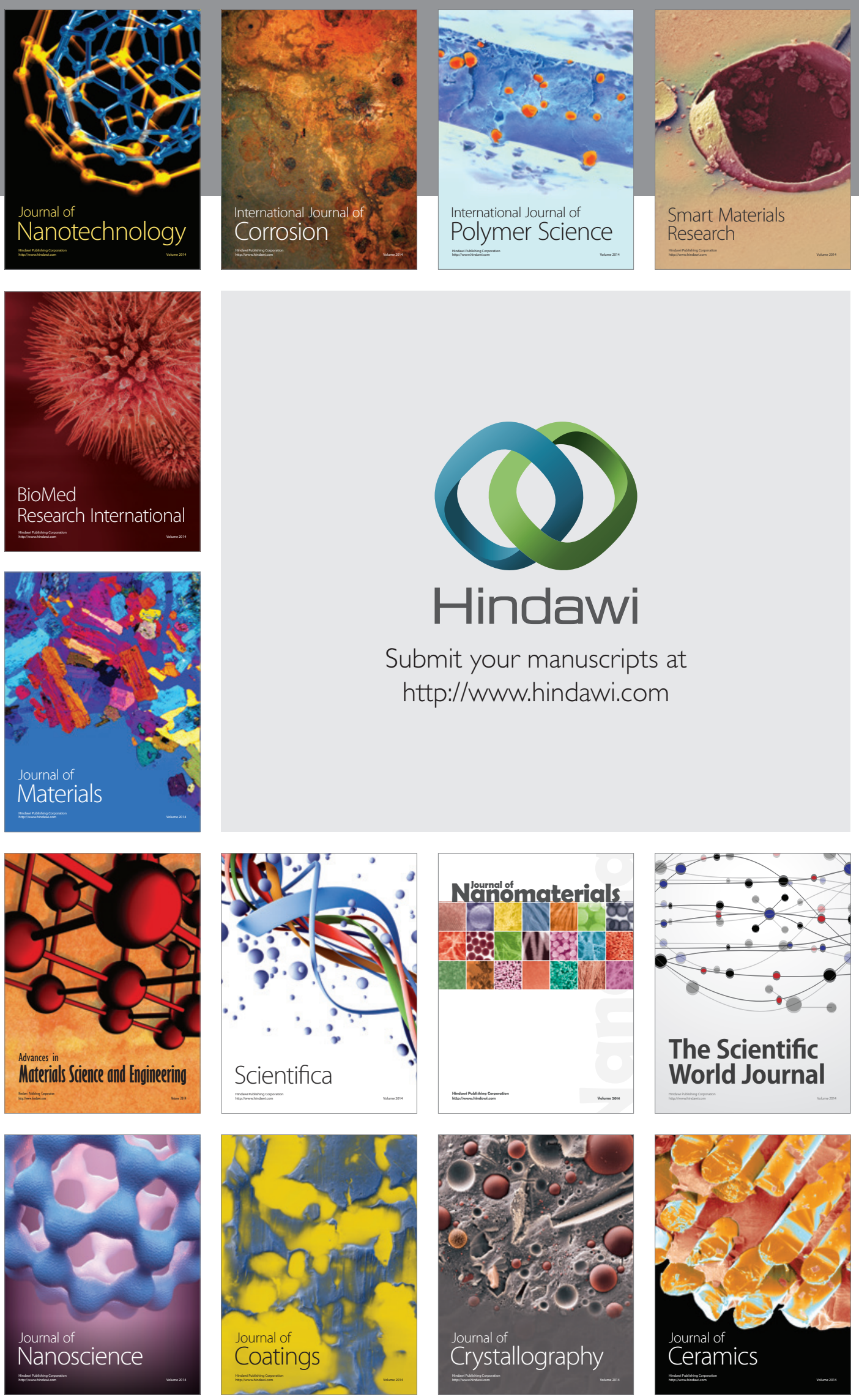

The Scientific World Journal

Submit your manuscripts at

http://www.hindawi.com

\section{World Journal}

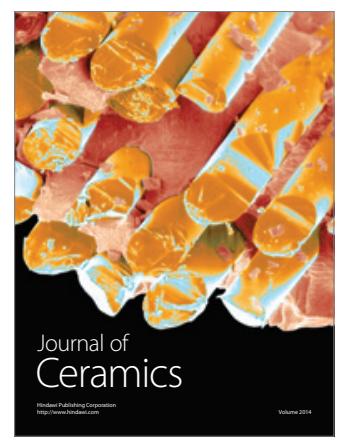

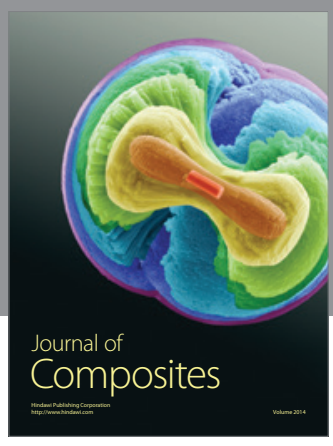
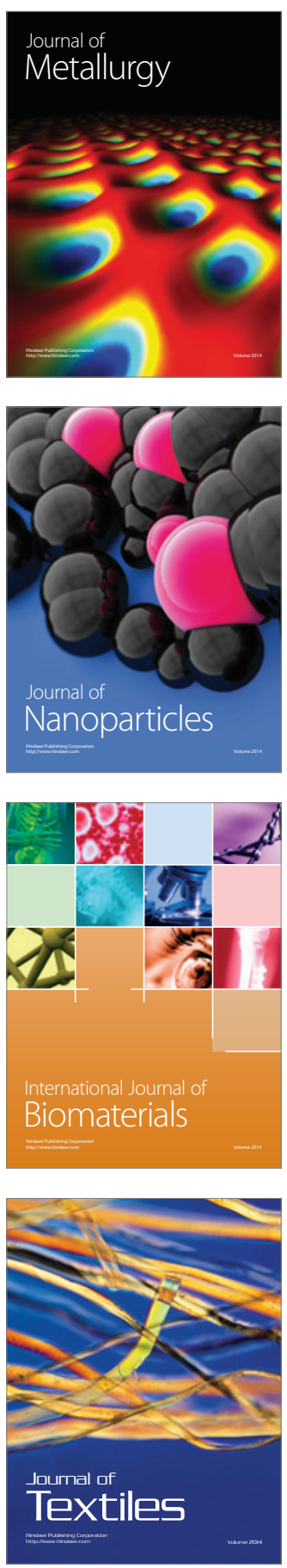